\title{
The Implications of the Recent Economic Crisis on Fertility in Greece
}

\author{
Byron Kotzamanis \\ Laboratory of Demographic and Social Analyses, University of Thessaly, Greece.
}

bkotz@prd. uth.gr

Anastasia Kostaki

Department of Statistics, Athens University of Economics and Business, Greece.

kostaki@aueb.gr

\begin{abstract}
A systematic review of past economic recessions occurred in developed countries confirms that social and economic crises often have serious effects on fertility while, beyond national differentiations, these effects have certain characteristics, e. g. a weak effect on generational fertility;an postponement on the timing of first birth, closely related to a late marriage or union;a close relationship between unemployment and age-specific fertility. The sensitivity of fertility behavior to economic crises is less marked in countries with longstanding family policies and strong social security systems. The recent social and economic recession in Greece took place under different social conditions than many recessions in the past. More women than ever are participating in the labor market, most couples use reliable contraception that enables them to postpone childbearing, while social security and health costs are burdened from the rapidly expanding numbers of elderly. All these factors can affect reproductive decisions and potentially aggravate the negative effects of the recession on fertility. This work, using the latest available official data of Greece, provides an investigation of the impact of the current economic crisis on fertility levels, as well as the evolution of these levels through time.
\end{abstract}

Keywords: Social and economic recession, fertility.

\section{Introduction}

The relationship between economic conditions and fertility is a classic research question in demography. The literature often mentions that fertility follows the cycles of the economy, while in times of economic downturn and uncertainty in the labor market, people are led to postpone childbearing, to adjust their family planning. (Goldstein, et al. , 2013; Adserà, 2004; Sobotka, Skirbekk \&Philipov, 2011; Hofmann \& Hohmeyer, 2012; Schmitt 2008 and 2012).

From a theoretical point of view, the issue that fertility 'react' positively in times of economic growth and "negative" in economic recessions has been discussed for over two centuries. Originally, Adam Smith in his work the "Wealth of Nations" in 1776, links the economic growth with the population growth. Becker (1960), studies the relation between fertility and income level. Easterlin $(1973,1976)$ considers fertility as a function of the economic environment of the younger generations, based on the experience they had during childhood years, living in the parental household.

In contrast of the above theories Butz and Ward (1979a, 1979b) analyzing data for the US fertility of the first half of the decade of 70 s, introduces the theory that fertility follows the opposite trend compared to the cycles of the economy. Considering the increasing participation of women in the labor market, he claims that the acquisition of a child in economic good times increases the "opportunity cost" for a woman. However, Macunovich (1996) argues that fertility remains linked to the cycles of the economy, while the negative effects of high unemployment during economic downturns are greater than any benefits of the reduction of " value " of women's work.

Nowadays, with the onset of the economic crisis in 2007-2008 in the US and the subsequent dissemination of European countries, the interest for exploring the relationship between economic crises and fertility is revived. 


\section{The current economic crisis and its background}

The literature suggests that economic downturns have an effect in changing fertility calendar, i. e. postponement of births, which results in reducing the total fertility rate and the number of children (Rindfuss, et al. , 1988; Andorka, 1978; Sobotka, 2008; Cutright \& Shorter, 1979; Morgan, 1991 and 1996).

However the current economic crisis is characterized by significant differences compared with the previous ones. First of all, it is the most intense and longest crisis than all the previous ones, while the current conditions are significantly different in comparison to crises of previous decades (in 20s or even in 70 s). Particularly in the late 2000 s, the welfare state is much more developed than it was for 50 or 100 years ago, the percentage of women in the labor market and their educational level are significantly higher than in the past decades, contraception tends to be generalized, and the mean age of the first childbearing is much higher than before. In most European countries is as high as 28 to 29 years, that is four to fivetimes, higher than in the 70s, allowing limited further postponing of childbearing for a woman. In a variety of countries, the economic crises are accompanied with simultaneous significant changes of the pension systems, e. g. reduction in the purchasing power of pensioners and increase of the upper age limits, that leads to a reduction of job opportunities for younger people and clearly lower salaries.

At the same time, the current crisis occurred at a time at which many countries have extremely low fertility levels, while in a part of them a small rise of these levels have been observedin recent pre crisis years (as for example Greece). The increase in fertility in Greece had started since the early 2000s, stabilized in 2009, decreasing thereafter from 1.55 children I woman in 2009, to 1.3 in 2014, while a same reversal is recorded in other countries (Bulgaria, Croatia, Czech Republic, Estonia, Latvia, Hungary, Romania, Spain, Italy, Portugal).

The differential intensity of the possible effects of the crisis in fertility levels can be attributed to the fact that before the crisis some countries had highly developed social safety nets and very strong family support policies resulting to minimize the effects of economic recessions (Thévenon, 2011; Fagnani, 2012).

The economic recession obviously affects first of all the younger part of the population that of reproductive ages. The unemployment rates at these ages reach extremely high levels, as a consequence of the crisis, and therefore this is highly likely to affect the reproductive behavior of young population. Usually, in this case a postponement of births is observed. The connection between economic recession and fertility seems to be strong in the southern countries, as well as in Eastern and Central Europe, whereas in the countries of Western and Northern Europe, where the impact of recession on the unemployment rates is limited, the current crisis and the slight rise of unemployment do not appear to have significant impact on fertility (Goldstein, et al. 2013).

Numerous studies referring to countries of central-eastern Europe confirm the above (UNECE, 2000; Philipov \& Dorbritz, 2003; Sobotka 2004 \& 2008a, b; Frejka, 2008), emphasizing the relationship between the effects of the economic recession and public policies of family support. These studies emphasize that the relationship between work (career) and fertility are less confrontational in social democratic and former socialist countries due probably to the strong institutional support to working mothers. In the "classic" social democratic welfare state of Nordic countries the combination of employment and motherhood does not pose particular problems not only due to high benefits and long parental leave but also because of the wider positive attitude / behavior towards working mothers (Matysiak \& Vignoli's, 2008). Finland had an exemplary policy that led to an increase in cross-sectional fertility in deep economic crisis (early 1990s). The introduction of a subsidy in the mid 1980s for parents who stay at home (child home-care allowance) for the care of their child (until the age of four) has considered as an attractive alternative to unemployment and limited job prospects for many women in the years of crises (Vikat, 2004).

Government policies can be effective in order to minimize or even to reverse the negative effects of the financial crisis in fertility according to Hoem (2000).

\section{The implications of the current economic crisis on fertility in Greece.}

\section{1. Data and methods}


The investigation of the potential impacts of the current economic crisis on the fertility levels of the population in Greece is based on analysis of the empirical data, provided by the Hellenic Statistical Authority (ELSTAT). These are,

- Number of births by five-year age group of mother,

- Number of births by five-year age group of mother and order of birth,

- Mean population sizes of women in reproductive ages by five-year age groups.

Although we have long time series for our analysis, we should note that the period from the onset of the crisis and beyond is relatively short (five years only, 2010-2014), while not yet available by ELSTAT data on births of 2014. This does not facilitate the investigation of potential impacts of the crisis on fertility.

Using the empirical data as described above, simple and complex classical demographic indicators are calculated, those are,

1. Fertility rates by age of mother,

2. Fertility rates by age of mother and order of birth,

3. Total annual fertility rate (synchronic analysis),

4. Mean age of mothers of childbearing (for first births and for all births).

\section{2. Results}

\section{2. 1 The evolution of fertility in post war Greece (1956-2013)}

From the end of the civil war (1949) until 1967, the number of births (Chart 1, Table 1 in Appendix) fluctuates at high levels. Specifically in 1949 births was 139. 108, while the very next year (the first after almost a decade of war status) will amount to 151134 and the next 17 years will stay around 150000-155000 to record in 1967 its highest value (162. 839). The next seven years its trend is downward (at 1973 equals 137 526), while during the first postwar period this number will increase from 144069 at 1974, to 148134 at 1980. But the following years it will significantly decline to 101167 in 1989 (32\% reduction since 1980), followed by a decade of relative stabilization at very low levels (around 100, 000 per year), despite the strong migratory flow from the former Eastern European countries. Finally, the first decade of 21 st century births will have an increasing trend (118 302 in 2008, that is 17. 5\% higher compared with 1999). However this trend that will halt thereafter. While in 2009 births exceeded 110, 000 from 2010 onwards will be progressively reduced, falling by $20 \%$ over the four last years. 
Figure 1: Greece, 1951-2013, Births (absolute numbers) kaı Crude Fertlity Rate (0/00)

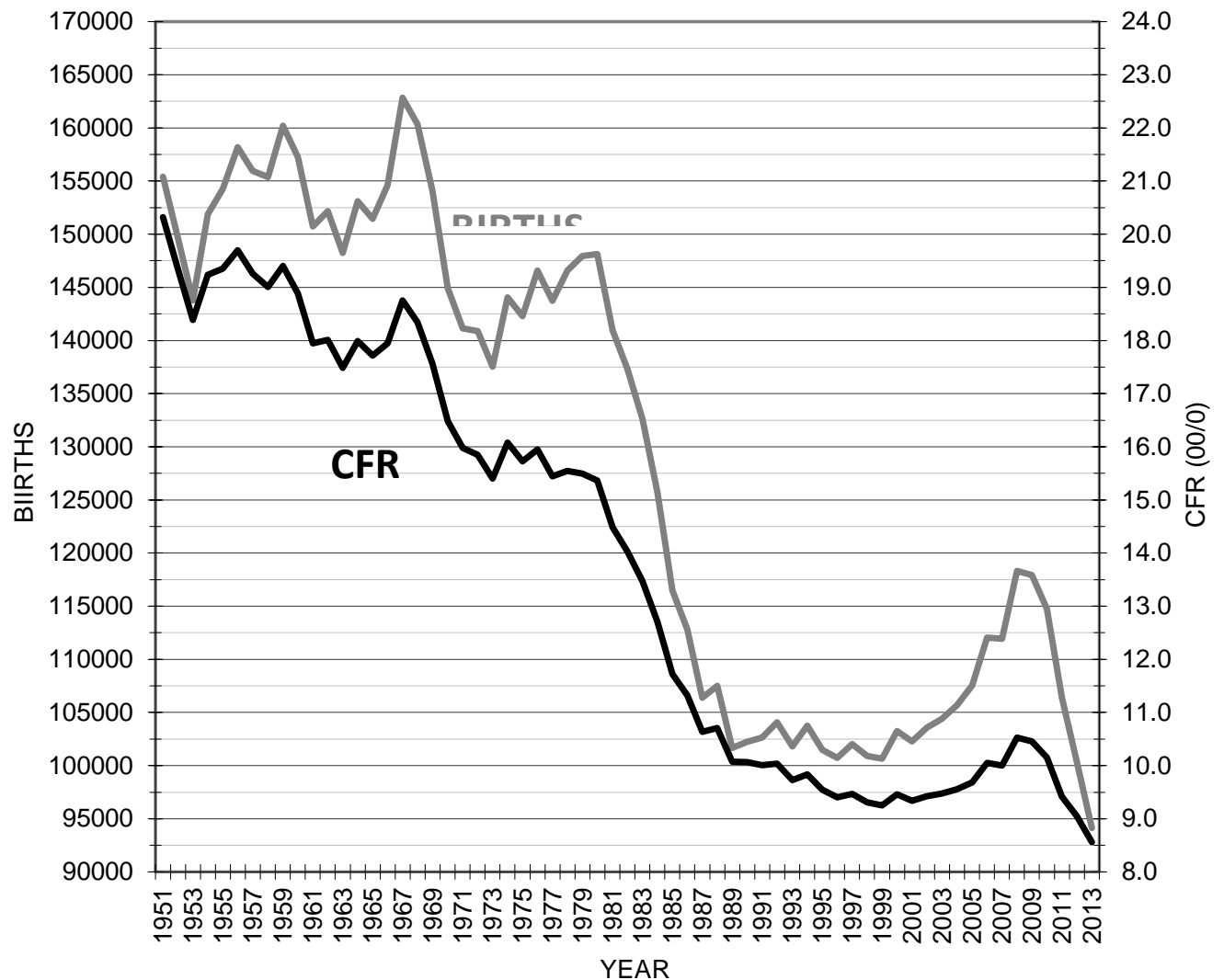

\subsubsection{Total Fertility Rate}

The Total Fertility Rate (TFR) indicating the average number of children per woman, (Figure 2, and Table 2, in Appendix), the first 30 years, until the early 1980s, recorded relatively high values (among the highest in European countries, namely 2. 2-2. 4 children per woman). In particular, at the beginning of the examined period TFR equals 2.31 children / woman and remains stable for a decade at levels higher the reproduction limit although with slight fluctuations since in 1967, when it reaches its highest value (2. 45). Then, after 1980, in a first period, TFR will record a rapid decline (at 1989 equals 1. 40 children / woman), resulting in the inclusion of Greece in the group of low fertility countries. The downward trend will continue clearly and slowly during the following decade, so in 1999 TFR takes its lowest value (1. 24 children / woman), leading to the accession of Greece, in accordance with the international bibliography, in countries with very low fertility (Lowest-Low Fertility). From the early years of 21th century TFR begins to recover (in 2005 will exceed 1.3 children / woman and 20082010 will roughly exceed 1.5 children/woman). However the increase of TFR will not further continue, while in 2013 its value will be significantly lower (1. 3 children / woman).

\subsubsection{Mean age of childbearing}

The mean age of childbearing in both all births as well as for first births, is characterized by considerable fluctuations (Table 2 in Appendix). The mean age for all births is high and relatively stable during the first postwar years while it declines from the early 1960s (decrease by 2.6 years between 1960 and 1981). This drop is obviously a result of continuous increasing 
of the age-specific fertility rates for younger reproductive ages ( $<25$ years) and the simultaneous decline of the corresponding rates in mature reproductive ages. But after a short time (until 1985) of relative stability the mean age will start to slowly increase at the beginning, but faster in following years, resulting togrow by about 5 years between 1985 and 2013 (26in 1985 to 30.9 in 2013). This increase is mainly due (up to the mid-1990s) to reduce of the age-specific fertility rates at younger ages, and from the late 1990s onwards, the increase of mean age at childbearing can be contributed to the increase of the age-specific fertility rates in mature reproductive ages.

Figure 2 (Mean age and TFR) capture the above described situation as it combines the intensity of the cross-sectional fertility with its calendar. The vertical drop of the curve from 1956 to 1981 and marks a period where the average age is constantly decreasing and the intensity of the cross-sectional fertility remains stable with slight fluctuations over the reproduction level (2.1 children per woman). Then for the four-year period $1981-1985$ there isa heavy fall of TFR and a stability of the mean age of birth and then for a longer period (1985 - 2001) the mean age of birth constantly increases while TFR constantly declines. From 2001-2010 there is an increase both in the mean age of birth and of TFR, while from 2010 the average age of birth increases and TFR falls.

Figure 2: Greece, Total Fertility rate versus mean age of childbearing (all births) 1960-2013

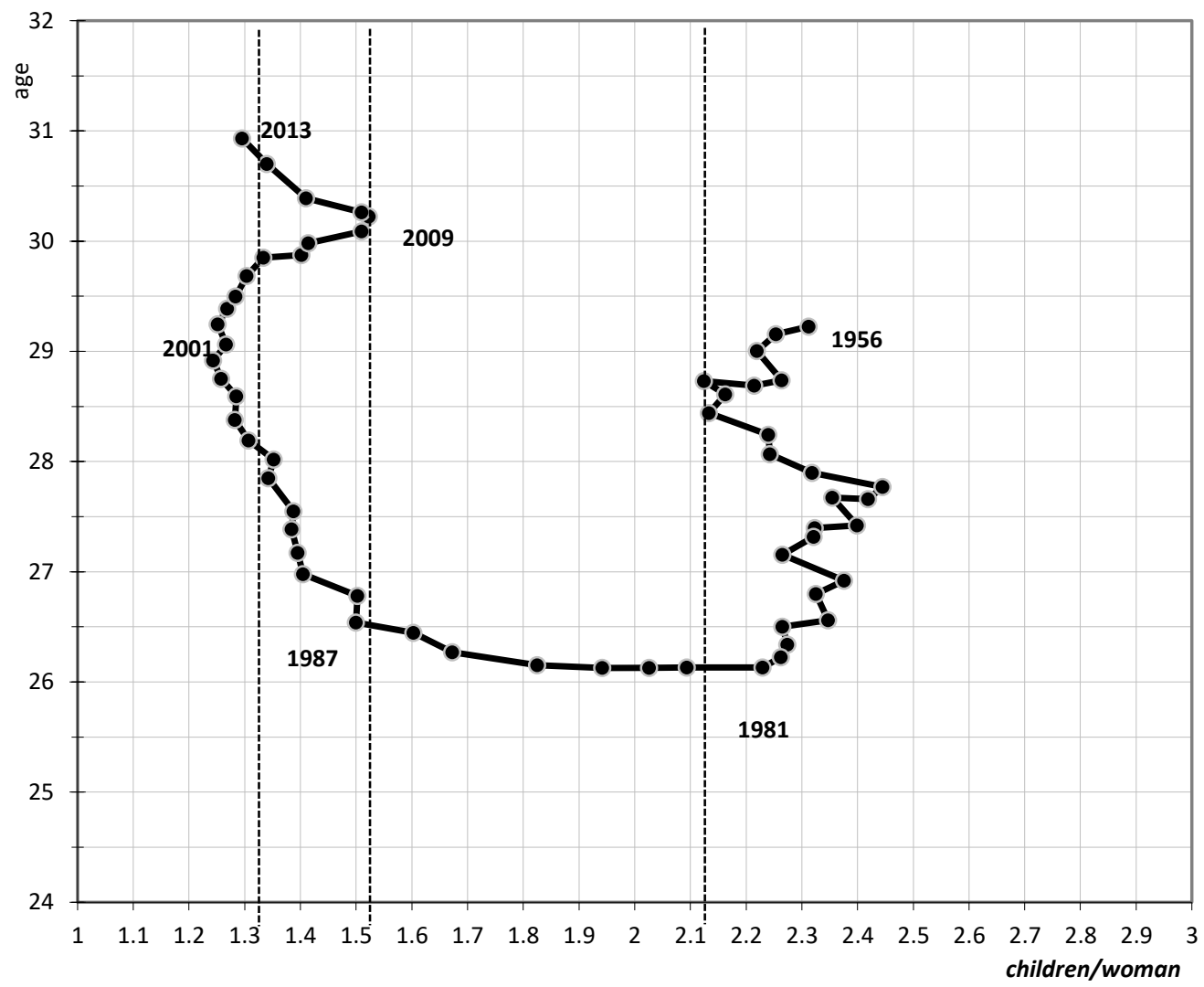

3.2.4 Age Specific Fertility Rates 
Figure 3 illustrates the progress of the age-specific fertility rates. A first view of the figure shows that the rates in the younger reproductive ages (years 15-24) exhibit an upward trend until the beginning of the 1980s, a trend that will be reversed in the next twenty years, leading them to collapse. The decline will halt temporarily for a short period (the 2000s) and will start again after 2010. Unlike the development of the age-specific rates of younger reproductive ages, the corresponding one for the later reproductive ages (> 30 years) will move initially downward, at the beginning of first decade of 21 th century and then upward. In recent years, however, coinciding with the onset of the economic crisis in Greece, it is becoming a common trend: the rates in almost all ages significantly decline. A special behavior and diversified development follow the rates at ages 26-29. These rates follow an upward trend (as those of ages below 25 years) but they strongly fail during the decade of $80 \mathrm{~s}$, while they exhibit some temporary signs of recovery in later years.

Figure 4, which illustrate the completed fertility in successive ages, show that the completed fertility in the age 25 until the late 70 s is increasing. Thereafter it is decreasing in all age groups. Figure 5 also confirms our previous conclusions, namely that the rise of TFR since 2000 - and in particular the differentiation in 2009 compared with 1999 is solely due to the increase of fertility levels of ages greater than 30 . The figure also clearly reflects all changes of fertility levels throughout the period considered, especially those of the last fifteen years, and also confirm that the increase of TFR since 2000 is solely due to declining fertility of younger ages and thatthe fall of TFRthereafteris due to declining fertility of all ages. Moreover it becomes obvious that though the high values of TFR until 1980 is due to young ages, their subsequent reduction is almost entirely due to the same ages, while this reduction does not offset until the late ' 90 s by increasing fertility of ages greater than 30 .

Figure 3: Greece. Age-Specific Fertility Rates (1960-2013)

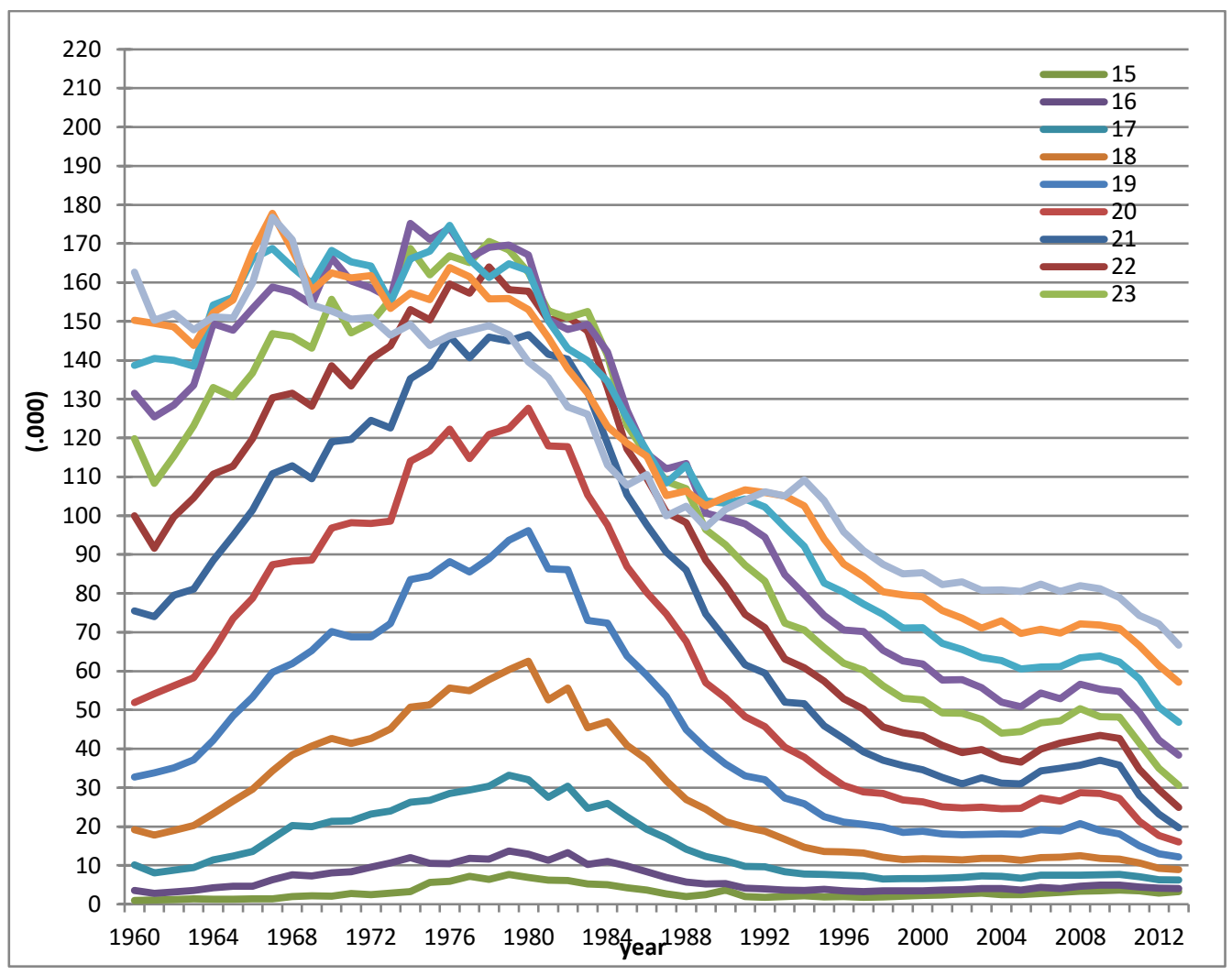




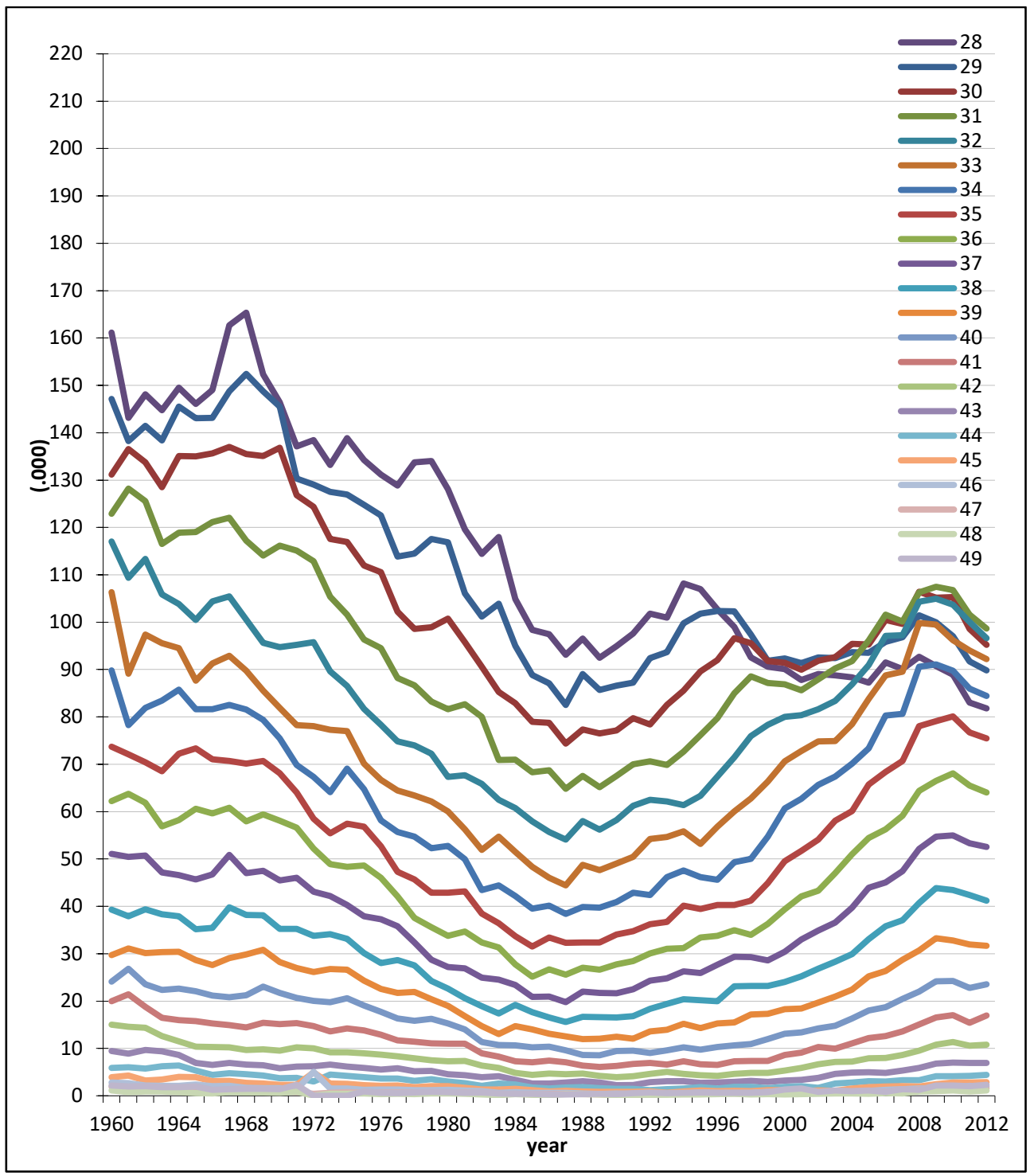


Figure4: Greece, completed fertility in successive ages for chosen years.

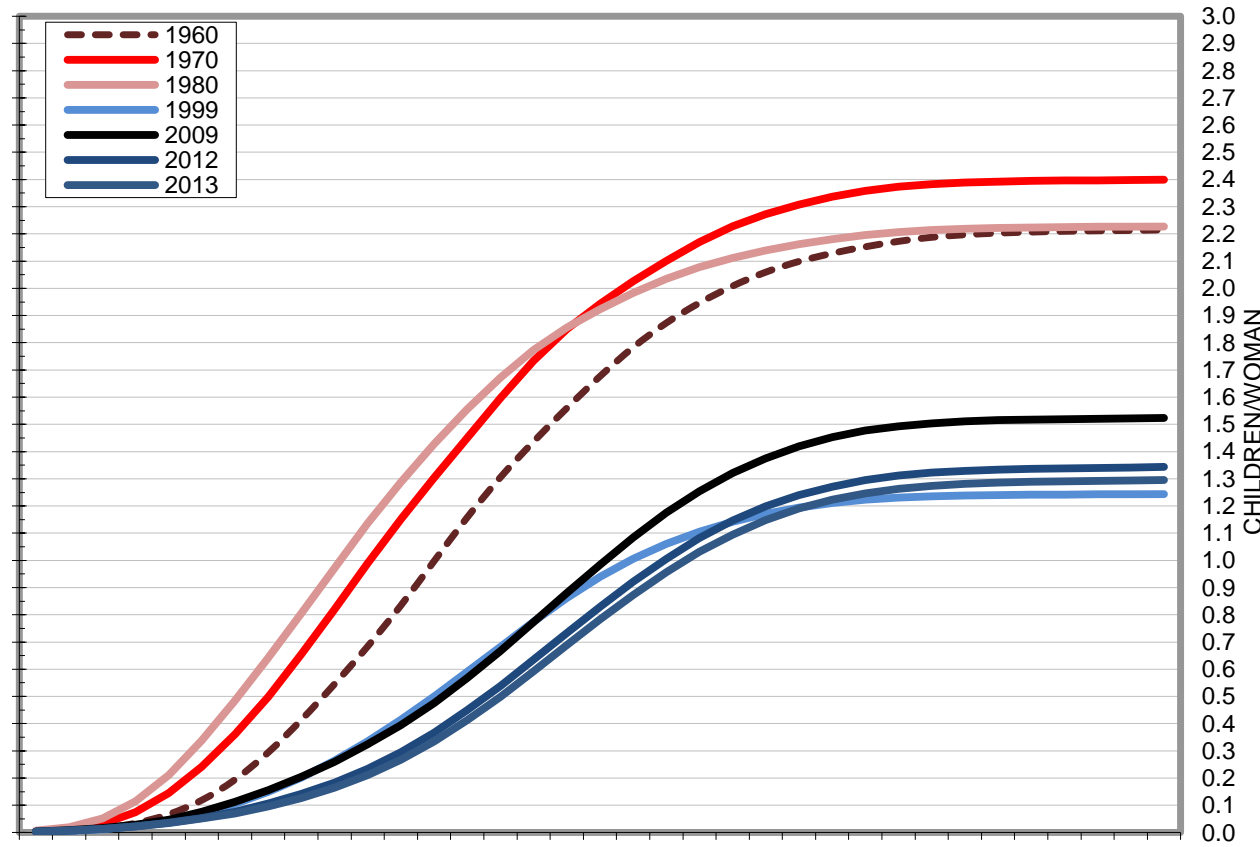

1516171819202122232425262728293031 32 A3 34353637383940414243444546474849

\section{2. 5. Fertility by birth order}

Analysis of fertility by birth order allows to consider a) whether -and to what extent, the reduction in cross-sectional fertility after 1980 resulted from the reduce of total births and whetherthere are signs of changing family patterns, particularly regarding childlessness and b) to formulate some hypotheses for the most recent periodafter 2009 (years of crisis).

Examining the evolution of births in the postwar period (Figure 5 and Table 3 in Appendix) we first find that the first order births steadily increase. In particular, the first births being $40 \%$ of total births in the 50 s, now (in 2013) represent $51 \%$ of the total, while the latter have risen slightly by the end of the 70 s (from $32-33 \%$ to $38 \%$ ) to then they stabilize. The steadily increasing participation of births of 1st and 2nd order clearly reflected in the figure, while in 1960 they are $73 \%$ of the total, from the mid-1970s they are $80 \%$ of total births, while inthe late 90 s they exceed $85 \%$ (89\% in 2013) of total births.

Births of $3^{\text {rd }}, 4^{\text {th }}$ or higher orders exhibit a relatively smooth progression and fewer fluctuations in relation to the first two classes by following, though with differentiated rates, a rough downtrend (faster decline of births of $4^{\text {th }}$ or higherorders in relation to those of $3^{\text {rd }}$ order). Specifically, unlike the first two births orders, $3^{\text {rd }}$ order births reduce slowly (from $15 \%$ in the 50 to $9 \%$ recently), and those of $4^{\text {th }}$ or higher orders are collapsing (from $13 \%$ to $3 \%$ ). It is worth noticed that in the 50 s births or $4^{\text {th }}$ or higher orders was around 20,000 , whereas those of 2013 just exceeded 3,000 . These trends are consistent with the apparently shrinking and gradual disappearance of large families. 
Figure 5 : Greece. Distribution of births by order (1960-2013)

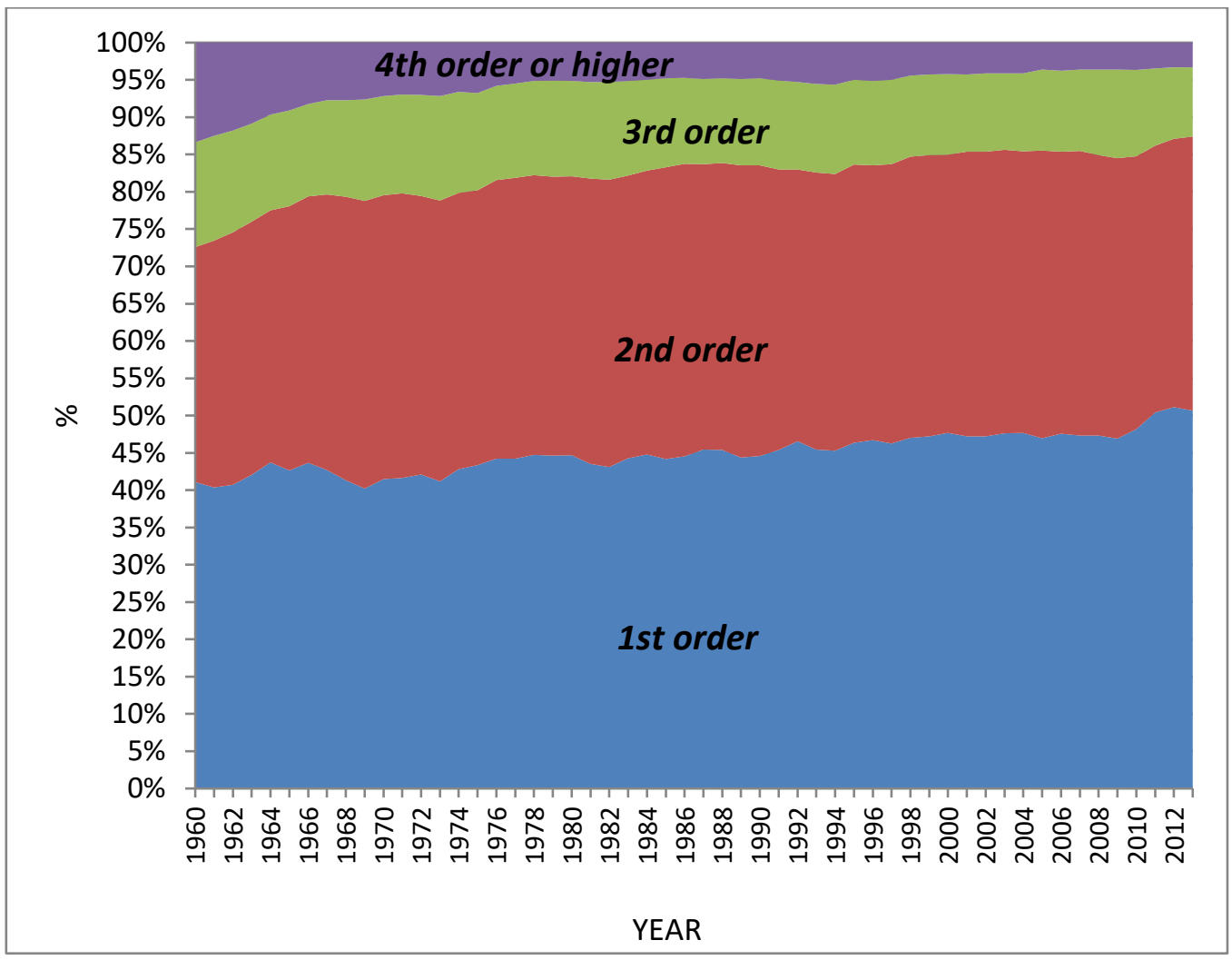

\subsubsection{Total Fertility Rates and Mean Age at Childbearing by order of birth}

First order TFR will experience a rapid growth in the beginning of the period (between 1960 and 1964) from 0.89 to 1. 00. In the next period (1964 -1980) it will stabilize more or less around the unit, while during ' 80 s it will significantly diminished by $40 \%,(0,98$ in 1980 and 0,62 at 1989). During the 90 s it will stabilize around 0.6 children/woman, followed by the mid2000 s rise (2010 $=0.75$ children/woman) while it will exhibit a small decline in the first years of the crisis (2011-2013).

Close if not identical progression- will follow TFR of $2^{\text {nd }}$ order. This indicator after a rising period $(0.69$ children / woman in 1960, 0.92 in 1970), it will stabilize in 1970 to collapse then during the 1980s (0.55 children/woman in 1989). The fall will continue at a milder pace than during the 90 s ( 0.47 children / woman in 1999) will be stopped thereafter while it will begin an upward trend after 2010. 
Figure 6: Greece, Total fertility rates differentiated by birth order (1960-2013)

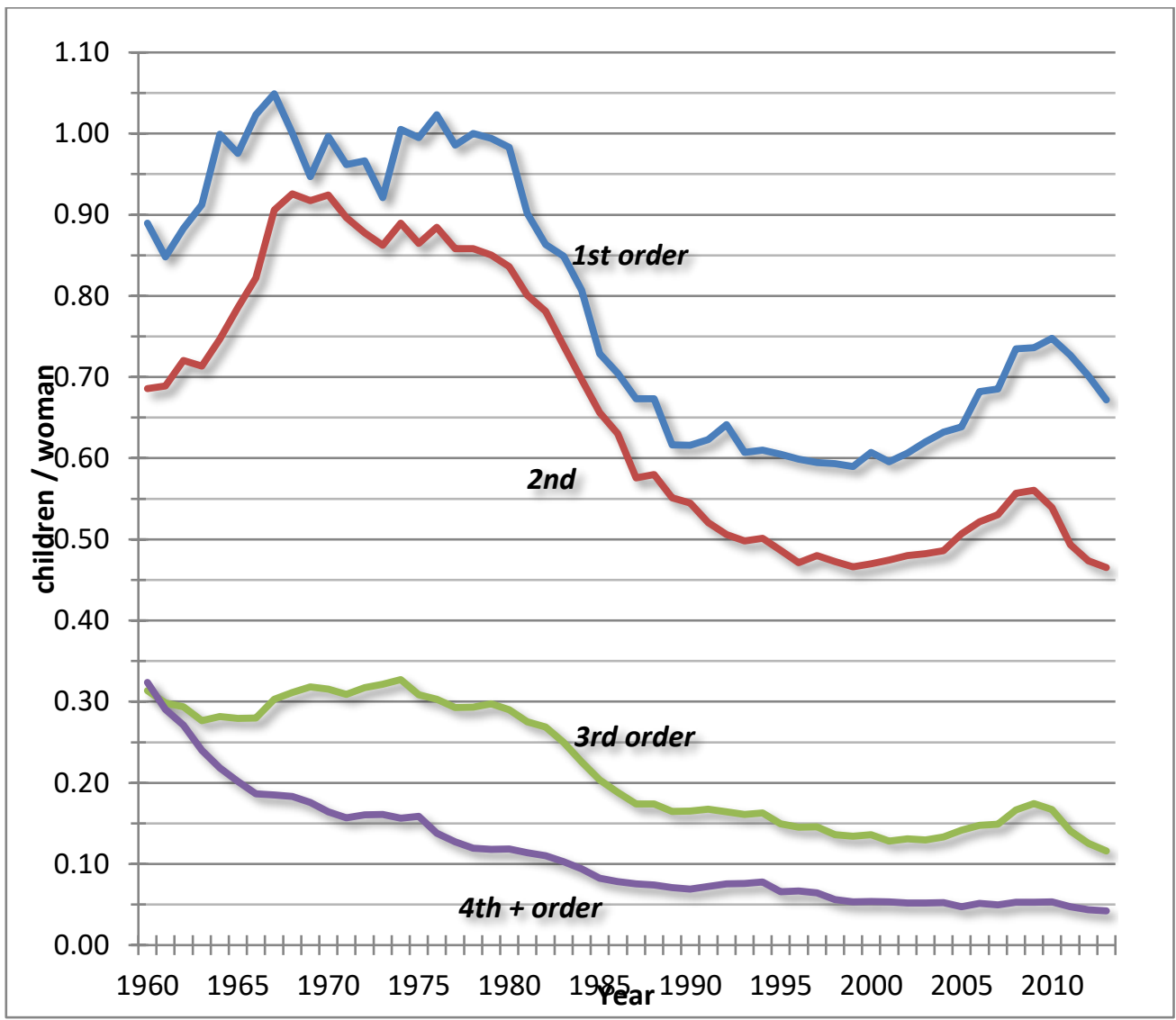

UnlikeTFR of $1^{\text {st }}$ and $2^{\text {nd }}$ order of births, that of $3^{\text {rd }}$ order will remain constant for about twenty years (around 0.3 children), thereafter it will be $50 \%$ lower between 1980 and 1989 (0.16 children), while it will stabilize thereafter around the value of 0.14 and it will slightly raise after 2005 (0.17 in 2010). Finally as regards TFR of $4^{\text {th }}$ class and above these will follow an uninterrupted downward trend throughout the period considered (0.32 in 1960 and 0.04 in 2013).

Our analysis shows that while the collapse of the total TFR during the 1980s is due to all orders of birth, the most significant "responsibility" have the indicators of $1^{\text {st }}$ and $2^{\text {nd }}$ orders. In particular, the reduction of TFR between 1980 and 1989 is due almost half (45\%) to the collapse of $1^{\text {st }}$ order TFR and secondarily the diminishing of $2^{\text {nd }}$ order TFR (participation 35\%). By extension, the declining values of indicators of $1^{\text {st }}$ and $2^{\text {nd }}$ order can be attributed almost by $80 \%$ to the reduction of the total cross-sectional fertility during the first period of its rapid collapse. Similarly, the increase in total TFR between 1999 and 2009 is by $52 \%$ due to the increase in $1^{\text {st }}$ order TFR, 34\% to the increase $2^{\text {nd }}$ order TFR and only $14 \%$ to the increase of the $3^{\text {rd }}$ order TFR. Finally, the reduction of the total TFR between the years of crisis (from 2010 and 2013) is solely due to the reduction of the corresponding TFRs of the first two orders.

Changes to mean age at birth by birth order are depicted in Figure 7 and Table 4 in Appendix. The average age drops to all orders of birth until the early-mid 1980s to reverse then for the births of $1^{\text {st }}, 2^{\text {nd }}$ and $3^{\text {rd }}$ order. Thus, the average age at $1^{\text {st }}$ order birth increases by 5.7 years between 1983 and 2013, while the average age of $2^{\text {nd }}$ birth increases by 5.3 years 
during the same period. These rises suggest an important change in the calendar of fertility of generations, i. e. a postponement of childbearing which is strongly associated with less total births.

Figure 7: Greece, Age of Mother by birth order (1960-2013)

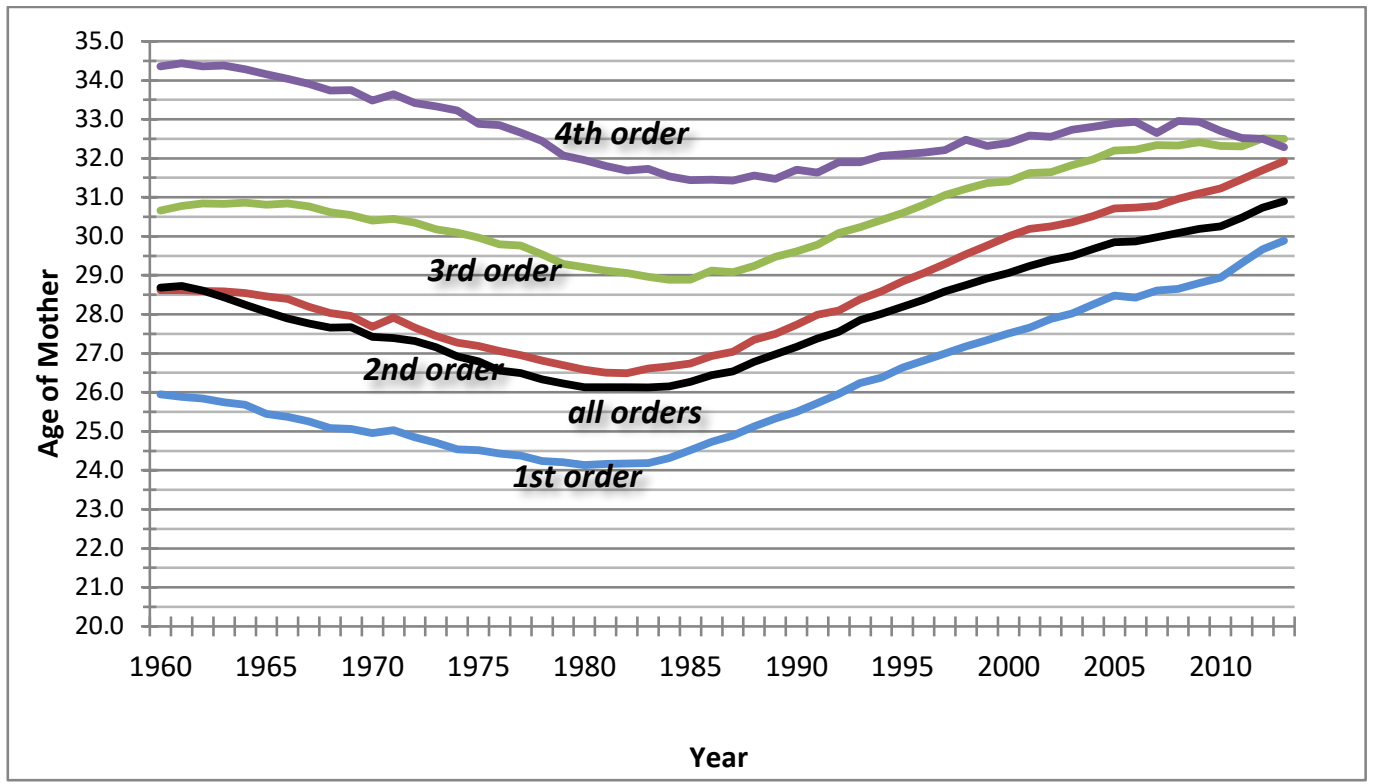

\section{The impact of economic crisis to fertility, first conclusions}

Our analysis shows that the collapse of the Total Fertility Rate (TFR) in Greece during the 80s was mainly due to the change of the women's fertility calendar as all generation until 1975 will record a TFR $>1.7$ children / woman (at least 4 decimal points higher than the lowest value of TFR noted in 1999). The growth of this indicator in the 2000s is solely due to a compensation of the postponement of births in the previous two decades and absolutely not to an increase of the average number of children in the younger generations. The recent reversal of the upward trend of TFR coincides indeed with the emergence of the financial crisis, however it cannot be attributed solely to it.

At the same time, in Greece, the available data indicate that the recent economic crisis is affecting in priority women under 30 years old (extreme high unemployment). However, this crisis coincided with a previous trend of increasing the mean age at the childbearing, started in the mid ' 80 s). This trend has resulted at 2013 to an extremely high average age at childbearing (30 years for the first child). Therefore, any continued postponement of childbearing to higher ages during the years of crisis (probable on the basis of international experience) will possibly lead to unavoidable fall of fertility of younger generations (i. e. those who were born after 1985) as, even if women of those generations aim to acquire one, two, three or more children, a part of them will not succeed it (any replacement is problematic as child conception is a function of age and decrease rapidly after 30 years old).

It should also be pointed out that childbearing occurs in Greece within marriage (the percentage of non-marital births is the lowest in Europe). Simultaneously, the mean age at first marriage follows the last thirty years an ascending course (from 23. 2 years in the mid-1980s to 29. 2 years in 2013). Based on the above, the mean age at first marriage and the mean age at first child birth are, directly correlated. Therefore, in a country like Greece, where childbearing occurs almost entirely within marriage with both partners employed, it was important for most women of these generations to have a relatively stable work before their first marriage and their first child acquisition. Given the extreme high unemployment rate in the age 
groups 20-35, this fact is not valid for a part of this population group, resulting to the collapse of the first marriage rates in recent years. As a direct result, we observe a further increase both of the percentage of unmarried women in younger generations and also of the average age at the first marriage. Both of them (the second in combination with the postponement of marital births) will inevitably lead to a further decline of the total fertility rate of younger generations of women (those born after 1985).

In conclusion, according to the international bibliography, in countries with strong social policies and especially policies supporting family and childbearing the negative effects of the crisis are diminished. In Greece, at the beginning of the crisis, the welfare state was not particularly developed and, at the same time, it was extremely inefficient. In this context, family and childbearing aid measures were very limited, focused almost exclusively on the large families ( $>3$ children) and in some cases these measures were inefficient (see for example retirement criteria for mothers with a minor child). The recent measures (those adapted in the first half of the current decade) were usually horizontal, while available policies resources shrank significantly while their rehabilitation is not expected in the near future. All these facts does not allow some optimism concerning the reversal of fertility decline of younger generations which, as expected, that they are going to spend a significant part of their reproductive life in crisis conditions.

\section{APPENDIX}

Table 1: Greece, 1951-2010, Number of births and Crude Birth Rate (CBR)

\begin{tabular}{|l|l|l|l|l|l|}
\hline Year & Births & CBR (oo/) & Year & Births & CBR (oo/o) \\
\hline 1951 & 155422 & 20,32 & 1983 & 132608 & 13,47 \\
\hline 1952 & 149637 & 19,35 & 1984 & 125724 & 12,70 \\
\hline 1953 & 143765 & 18,39 & 1985 & 116481 & 11,73 \\
\hline 1954 & 151892 & 19,23 & 1986 & 112810 & 11,32 \\
\hline 1955 & 154263 & 19,35 & 1987 & 106392 & 10,64 \\
\hline 1956 & 158203 & 19,70 & 1988 & 107505 & 10,71 \\
\hline 1957 & 155940 & 19,26 & 1989 & 101657 & 10,08 \\
\hline 1958 & 155359 & 19,01 & 1990 & 102229 & 10,07 \\
\hline 1959 & 160199 & 19,40 & 1991 & 102620 & 10,01 \\
\hline 1960 & 157239 & 18,88 & 1992 & 104081 & 10,04 \\
\hline 1961 & 150716 & 17,95 & 1993 & 101799 & 9,73 \\
\hline 1962 & 152158 & 18,01 & 1994 & 103763 & 9,83 \\
\hline 1963 & 148249 & 17,48 & 1995 & 101495 & 9,54 \\
\hline 1964 & 153109 & 17,99 & 1996 & 100718 & 9,40 \\
\hline 1965 & 151448 & 17,71 & 1997 & 102038 & 9,47 \\
\hline 1966 & 154613 & 17,95 & 1998 & 100894 & 9,31 \\
\hline 1967 & 162839 & 18,75 & 1999 & 100643 & 9,25 \\
\hline 1968 & 160338 & 18,34 & 2000 & 103267 & 9,46 \\
\hline 1969 & 154077 & 17,56 & 2001 & 102282 & 9,34 \\
\hline 1970 & 144928 & 16,48 & 2002 & 103569 & 9,43 \\
\hline 1971 & 141126 & 15,98 & 2003 & 104420 & 9,47 \\
\hline 1972 & 140891 & 15,85 & 2004 & 105655 & 9,55 \\
\hline 1973 & 137526 & 15,40 & 2005 & 107545 & 9,69 \\
\hline 1974 & 144069 & 16,08 & 2006 & 112042 & 10,05 \\
\hline & & & & & \\
\hline
\end{tabular}




\begin{tabular}{|l|l|l|l|l|l|}
1975 & 142273 & 15,73 & 2007 & 111926 & 10,00 \\
\hline 1976 & 146566 & 15,95 & 2008 & 118302 & 10,53 \\
\hline 1977 & 143739 & 15,44 & 2009 & 117933 & 10,45 \\
\hline 1978 & 146588 & 15,54 & 2010 & 114766 & 10,15 \\
\hline 1979 & 147965 & 15,50 & 2011 & 106428 & 9,42 \\
\hline 1980 & 148134 & 15,36 & 2012 & 100371 & 9,05 \\
\hline 1981 & 140953 & 14,49 & 2013 & 94134 & 8,56 \\
\hline
\end{tabular}

Table 2: Greece, Total Fertility Rate (TFR) and mean age at childbearing (i) all births (ii) $1^{\text {st }}$ order births (1960-2013)

\begin{tabular}{|c|c|c|c|c|c|c|c|}
\hline Year & TFR & Mean Age & $\begin{array}{l}\text { Mean age of } \\
\text { mother of } 1 \text { st order } \\
\text { births }\end{array}$ & Year & TFR & Mean Age & $\begin{array}{l}\text { Mean age of mother of } \\
1 \text { st order birth }\end{array}$ \\
\hline 1956 & 2, 31 & 29,2 & & 1985 & 1,67 & 26,3 & 24,5 \\
\hline 1957 & 2,25 & 29,2 & & 1986 & 1,60 & 26,4 & 24,7 \\
\hline 1958 & 2, 22 & 29,0 & & 1987 & 1,50 & 26,5 & 24,9 \\
\hline 1959 & 2, 26 & 28,7 & & 1988 & 1,50 & 26,8 & 25,1 \\
\hline 1960 & 2,21 & 28,7 & 25,9 & 1989 & 1,40 & 27,0 & 25,3 \\
\hline 1961 & 2,12 & 28,7 & 25,9 & 1990 & 1,40 & 27,2 & 25,5 \\
\hline 1962 & 2,16 & 28,6 & 25,8 & 1991 & 1,38 & 27,4 & 25,7 \\
\hline 1963 & 2,13 & 28,4 & 25,7 & 1992 & 1,39 & 27,5 & 26,0 \\
\hline 1964 & 2,24 & 28,2 & 25,7 & 1993 & 1,34 & 27,8 & 26,2 \\
\hline 1965 & 2,24 & 28,1 & 25,4 & 1994 & 1,35 & 28,0 & 26,4 \\
\hline 1966 & 2,32 & 27,9 & 25,4 & 1995 & 1,31 & 28,2 & 26,6 \\
\hline 1967 & 2,45 & 27,8 & 25,3 & 1996 & 1,28 & 28,4 & 26,8 \\
\hline 1968 & 2,42 & 27,7 & 25,1 & 1997 & 1,29 & 28,6 & 27,0 \\
\hline 1969 & 2,35 & 27,7 & 25,1 & 1998 & 1,26 & 28,8 & 27,2 \\
\hline 1970 & 2,40 & 27,4 & 25,0 & 1999 & 1,24 & 28,9 & 27,3 \\
\hline 1971 & 2,32 & 27,4 & 25,0 & 2000 & 1,27 & 29,1 & 27,5 \\
\hline 1972 & 2,32 & 27,3 & 24,8 & 2001 & 1,25 & 29,2 & 27,7 \\
\hline 1973 & 2,27 & 27,2 & 24,7 & 2002 & 1,27 & 29,4 & 27,9 \\
\hline 1974 & 2,38 & 26,9 & 24,5 & 2003 & 1,28 & 29,5 & 28,0 \\
\hline 1975 & 2,33 & 26,8 & 24,5 & 2004 & 1,30 & 29,7 & 28,3 \\
\hline 1976 & 2,35 & 26,6 & 24,4 & 2005 & 1,33 & 29,8 & 28,5 \\
\hline 1977 & 2,27 & 26,5 & 24,4 & 2006 & 1,40 & 29,9 & 28,4 \\
\hline 1978 & 2,27 & 26,3 & 24,2 & 2007 & 1,41 & 30,0 & 28,6 \\
\hline 1979 & 2,26 & 26,2 & 24,2 & 2008 & 1,51 & 30,1 & 28,7 \\
\hline 1980 & 2,23 & 26,1 & 24,1 & 2009 & 1,52 & 30,2 & 28,8 \\
\hline 1981 & 2,09 & 26,1 & 24,2 & 2010 & 1,51 & 30,3 & 28,9 \\
\hline 1982 & 2,03 & 26,1 & 24,2 & 2011 & 1,41 & 30,4 & 29,3 \\
\hline
\end{tabular}




\begin{tabular}{|l|l|l|l|l|l|l|l|}
1983 & 1,94 & 26,1 & 24,2 & 2012 & 1,34 & 30,7 & 29,7 \\
\hline 1984 & 1,83 & 26,2 & 24,3 & 2013 & 1,30 & 30,9 & 29,9 \\
\hline
\end{tabular}

Table 3: Greece, Births by order.

\begin{tabular}{|c|c|c|c|c|c|c|c|c|}
\hline Year & 1st order & $\begin{array}{l}\% \\
1 s t \\
\text { order }\end{array}$ & $2^{\text {nd }}$ order & $\% 2^{\text {nd }}$ order & $3^{\text {nnd }}$ order & $\% 3^{\text {nd }}$ order & $\begin{array}{l}4^{\text {nd }}+ \\
\text { order }\end{array}$ & $\% 4^{n d}+$ order \\
\hline 1960 & 64553 & $41 \%$ & 49577 & $32 \%$ & 22104 & $14 \%$ & 21005 & $13 \%$ \\
\hline 1961 & 60805 & $40 \%$ & 49888 & $33 \%$ & 21157 & $14 \%$ & 18866 & $13 \%$ \\
\hline 1962 & 61958 & $41 \%$ & 51518 & $34 \%$ & 20776 & $14 \%$ & 17906 & $12 \%$ \\
\hline 1963 & 62357 & $42 \%$ & 50284 & $34 \%$ & 19527 & $13 \%$ & 16081 & $11 \%$ \\
\hline 1964 & 66952 & $44 \%$ & 51706 & $34 \%$ & 19686 & $13 \%$ & 14765 & $10 \%$ \\
\hline 1965 & 64594 & $43 \%$ & 53671 & $35 \%$ & 19430 & $13 \%$ & 13753 & $9 \%$ \\
\hline 1966 & 67520 & $44 \%$ & 55232 & $36 \%$ & 19146 & $12 \%$ & 12715 & $8 \%$ \\
\hline 1967 & 69496 & $43 \%$ & 60218 & $37 \%$ & 20543 & $13 \%$ & 12582 & $8 \%$ \\
\hline 1968 & 66284 & $41 \%$ & 60893 & $38 \%$ & 20779 & $13 \%$ & 12382 & $8 \%$ \\
\hline 1969 & 61955 & $40 \%$ & 59424 & $39 \%$ & 20930 & $14 \%$ & 11768 & $8 \%$ \\
\hline 1970 & 60141 & $41 \%$ & 55155 & $38 \%$ & 19240 & $13 \%$ & 10392 & $7 \%$ \\
\hline 1971 & 58744 & $42 \%$ & 53832 & $38 \%$ & 18727 & $13 \%$ & 9823 & $7 \%$ \\
\hline 1972 & 59336 & $42 \%$ & 52571 & $37 \%$ & 19087 & $14 \%$ & 9897 & $7 \%$ \\
\hline 1973 & 56646 & $41 \%$ & 51753 & $38 \%$ & 19256 & $14 \%$ & 9871 & $7 \%$ \\
\hline 1974 & 61633 & $43 \%$ & 53393 & $37 \%$ & 19547 & $14 \%$ & 9496 & $7 \%$ \\
\hline 1975 & 61681 & $43 \%$ & 52428 & $37 \%$ & 18539 & $13 \%$ & 9625 & $7 \%$ \\
\hline 1976 & 64798 & $44 \%$ & 54756 & $37 \%$ & 18534 & $13 \%$ & 8478 & $6 \%$ \\
\hline 1977 & 63577 & $44 \%$ & 54087 & $38 \%$ & 18182 & $13 \%$ & 7893 & $5 \%$ \\
\hline 1978 & 65541 & $45 \%$ & 55015 & $38 \%$ & 18530 & $13 \%$ & 7502 & $5 \%$ \\
\hline 1979 & 66056 & $45 \%$ & 55330 & $37 \%$ & 19067 & $13 \%$ & 7512 & $5 \%$ \\
\hline 1980 & 66169 & $45 \%$ & 55396 & $37 \%$ & 18934 & $13 \%$ & 7635 & $5 \%$ \\
\hline 1981 & 61360 & $44 \%$ & 53879 & $38 \%$ & 18258 & $13 \%$ & 7456 & $5 \%$ \\
\hline 1982 & 59192 & $43 \%$ & 52884 & $39 \%$ & 17967 & $13 \%$ & 7232 & $5 \%$ \\
\hline 1983 & 58686 & $44 \%$ & 50302 & $38 \%$ & 16827 & $13 \%$ & 6793 & $5 \%$ \\
\hline 1984 & 56312 & $45 \%$ & 47832 & $38 \%$ & 15314 & $12 \%$ & 6266 & $5 \%$ \\
\hline 1985 & 51436 & $44 \%$ & 45566 & $39 \%$ & 13926 & $12 \%$ & 5553 & $5 \%$ \\
\hline 1986 & 50233 & $45 \%$ & 44236 & $39 \%$ & 13017 & $12 \%$ & 5324 & $5 \%$ \\
\hline 1987 & 48344 & $45 \%$ & 40724 & $38 \%$ & 12139 & $11 \%$ & 5185 & $5 \%$ \\
\hline 1988 & 48770 & $45 \%$ & 41372 & $38 \%$ & 12237 & $11 \%$ & 5126 & $5 \%$ \\
\hline 1989 & 45102 & $44 \%$ & 39826 & $39 \%$ & 11748 & $12 \%$ & 4981 & $5 \%$ \\
\hline 1990 & 45588 & $45 \%$ & 39833 & $39 \%$ & 11914 & $12 \%$ & 4894 & $5 \%$ \\
\hline 1991 & 46583 & $45 \%$ & 38558 & $38 \%$ & 12262 & $12 \%$ & 5217 & $5 \%$ \\
\hline 1992 & 48450 & $47 \%$ & 37947 & $36 \%$ & 12166 & $12 \%$ & 5518 & $5 \%$ \\
\hline 1993 & 46276 & $45 \%$ & 37771 & $37 \%$ & 12094 & $12 \%$ & 5658 & $6 \%$ \\
\hline 1994 & 46978 & $45 \%$ & 38478 & $37 \%$ & 12429 & $12 \%$ & 5878 & $6 \%$ \\
\hline 1995 & 47056 & $46 \%$ & 37828 & $37 \%$ & 11564 & $11 \%$ & 5047 & $5 \%$ \\
\hline 1996 & 47067 & $47 \%$ & 37068 & $37 \%$ & 11396 & $11 \%$ & 5187 & $5 \%$ \\
\hline 1997 & 47176 & $46 \%$ & 38228 & $37 \%$ & 11562 & $11 \%$ & 5072 & $5 \%$ \\
\hline 1998 & 47450 & $47 \%$ & 38048 & $38 \%$ & 10910 & $11 \%$ & 4486 & $4 \%$ \\
\hline 1999 & 47525 & $47 \%$ & 37915 & $38 \%$ & 10901 & $11 \%$ & 4302 & $4 \%$ \\
\hline 2000 & 49229 & $48 \%$ & 38536 & $37 \%$ & 11131 & $11 \%$ & 4371 & $4 \%$ \\
\hline 2001 & 48268 & $47 \%$ & 39078 & $38 \%$ & 10566 & $10 \%$ & 4370 & $4 \%$ \\
\hline
\end{tabular}




\begin{tabular}{|l|l|l|l|l|l|l|l|l|}
2002 & 48900 & $47 \%$ & 39543 & $38 \%$ & 10841 & $10 \%$ & 4285 & $4 \%$ \\
\hline 2003 & 49729 & $48 \%$ & 39696 & $38 \%$ & 10709 & $10 \%$ & 4286 & $4 \%$ \\
\hline 2004 & 50389 & $48 \%$ & 39884 & $38 \%$ & 11036 & $10 \%$ & 4346 & $4 \%$ \\
\hline 2005 & 50528 & $47 \%$ & 41434 & $39 \%$ & 11682 & $11 \%$ & 3901 & $4 \%$ \\
\hline 2006 & 53323 & $48 \%$ & 42350 & $38 \%$ & 12128 & $11 \%$ & 4241 & $4 \%$ \\
\hline 2007 & 52981 & $47 \%$ & 42712 & $38 \%$ & 12171 & $11 \%$ & 4062 & $4 \%$ \\
\hline 2008 & 55995 & $47 \%$ & 44484 & $38 \%$ & 13536 & $11 \%$ & 4287 & $4 \%$ \\
\hline 2009 & 55328 & $47 \%$ & 44322 & $38 \%$ & 14042 & $12 \%$ & 4241 & $4 \%$ \\
\hline 2010 & 55296 & $48 \%$ & 42002 & $37 \%$ & 13235 & $12 \%$ & 4233 & $4 \%$ \\
\hline 2011 & 53632 & $50 \%$ & 38117 & $36 \%$ & 10997 & $10 \%$ & 3682 & $3 \%$ \\
\hline 2012 & 51317 & $51 \%$ & 36085 & $36 \%$ & 9639 & $10 \%$ & 3330 & $3 \%$ \\
\hline 2013 & 47675 & $51 \%$ & 34614 & $37 \%$ & 8715 & $9 \%$ & 3130 & $3 \%$ \\
\hline
\end{tabular}

Table 4: Greece, 1960-2013, TFR and mean age at childbearing by birth order

\begin{tabular}{|l|l|l|l|l|l|l|l|l|}
\hline & \multicolumn{9}{|l|}{ TFR } & \multicolumn{5}{l|}{ Mean age at childbearing } \\
\hline Year & 1storder & $\begin{array}{l}\text { 2ng } \\
\text { order }\end{array}$ & 3rd order & 4th or higher order & $\begin{array}{l}\text { 1storde } \\
\text { r }\end{array}$ & $\begin{array}{l}\text { 2ng } \\
\text { order }\end{array}$ & $\begin{array}{l}\text { 3rd } \\
\text { order }\end{array}$ & 4th or higher order \\
\hline 1960 & 0,89 & 0,69 & 0,31 & 0,32 & 25,9 & 28,6 & 30,7 & 34,4 \\
\hline 1961 & 0,85 & 0,69 & 0,30 & 0,29 & 25,9 & 28,6 & 30,8 & 34,4 \\
\hline 1962 & 0,88 & 0,72 & 0,29 & 0,27 & 25,8 & 28,6 & 30,8 & 34,4 \\
\hline 1963 & 0,91 & 0,71 & 0,28 & 0,24 & 25,7 & 28,6 & 30,8 & 34,4 \\
\hline 1964 & 1,00 & 0,75 & 0,28 & 0,22 & 25,7 & 28,6 & 30,9 & 34,3 \\
\hline 1965 & 0,98 & 0,79 & 0,28 & 0,20 & 25,4 & 28,5 & 30,8 & 34,2 \\
\hline 1966 & 1,02 & 0,82 & 0,28 & 0,19 & 25,4 & 28,4 & 30,8 & 34,0 \\
\hline 1967 & 1,05 & 0,91 & 0,30 & 0,19 & 25,3 & 28,2 & 30,8 & 33,9 \\
\hline 1968 & 1,00 & 0,93 & 0,31 & 0,18 & 25,1 & 28,0 & 30,6 & 33,7 \\
\hline 1969 & 0,95 & 0,92 & 0,32 & 0,18 & 25,1 & 28,0 & 30,5 & 33,7 \\
\hline 1970 & 1,00 & 0,92 & 0,32 & 0,16 & 25,0 & 27,7 & 30,4 & 33,5 \\
\hline 1971 & 0,96 & 0,90 & 0,31 & 0,16 & 25,0 & 27,9 & 30,4 & 33,6 \\
\hline 1972 & 0,97 & 0,88 & 0,32 & 0,16 & 24,8 & 27,7 & 30,4 & 33,4 \\
\hline 1973 & 0,92 & 0,86 & 0,32 & 0,16 & 24,7 & 27,4 & 30,2 & 33,3 \\
\hline 1974 & 1,01 & 0,89 & 0,33 & 0,16 & 24,5 & 27,3 & 30,1 & 33,2 \\
\hline 1975 & 1,00 & 0,86 & 0,31 & 0,16 & 24,5 & 27,2 & 30,0 & 32,9 \\
\hline 1976 & 1,02 & 0,88 & 0,30 & 0,14 & 24,4 & 27,1 & 29,8 & 32,9 \\
\hline 1977 & 0,99 & 0,86 & 0,29 & 0,13 & 27,0 & 29,8 & 32,7 \\
\hline 1978 & 1,00 & 0,86 & 0,29 & 0,12 & 24,2 & 26,7 & 29,3 & 32,1 \\
\hline 1979 & 0,99 & 0,85 & 0,30 & 0,12 & & & & 32,5 \\
\hline
\end{tabular}




\begin{tabular}{|c|c|c|c|c|c|c|c|c|}
\hline 1980 & 0,98 & 0,84 & 0,29 & 0,12 & 24,1 & 26,6 & 29,2 & 32,0 \\
\hline 1981 & 0,90 & 0,80 & 0,28 & 0,11 & 24,2 & 26,5 & 29,1 & 31,8 \\
\hline 1982 & 0,86 & 0,78 & 0,27 & 0,11 & 24,2 & 26,5 & 29,1 & 31,7 \\
\hline 1983 & 0,85 & 0,74 & 0,25 & 0,10 & 24,2 & 26,6 & 29,0 & 31,7 \\
\hline 1984 & 0,81 & 0,70 & 0,23 & 0,09 & 24,3 & 26,7 & 28,9 & 31,5 \\
\hline 1985 & 0,73 & 0,66 & 0,20 & 0,08 & 24,5 & 26,7 & 28,9 & 31,4 \\
\hline 1986 & 0,70 & 0,63 & 0,19 & 0,08 & 24,7 & 26,9 & 29,1 & 31,5 \\
\hline 1987 & 0,67 & 0,58 & 0,17 & 0,08 & 24,9 & 27,0 & 29,1 & 31,4 \\
\hline 1988 & 0,67 & 0,58 & 0,17 & 0,07 & 25,1 & 27,3 & 29,2 & 31,6 \\
\hline 1989 & 0,62 & 0,55 & 0,16 & 0,07 & 25,3 & 27,5 & 29,5 & 31,5 \\
\hline 1990 & 0,62 & 0,54 & 0,17 & 0,07 & 25,5 & 27,7 & 29,6 & 31,7 \\
\hline 1991 & 0,62 & 0,52 & 0,17 & 0,07 & 25,7 & 28,0 & 29,8 & 31,6 \\
\hline 1992 & 0,64 & 0,51 & 0,16 & 0,08 & 26,0 & 28,1 & 30,1 & 31,9 \\
\hline 1993 & 0,61 & 0,50 & 0,16 & 0,08 & 26,2 & 28,4 & 30,2 & 31,9 \\
\hline 1994 & 0,61 & 0,50 & 0,16 & 0,08 & 26,4 & 28,6 & 30,4 & 32,1 \\
\hline 1995 & 0,60 & 0,49 & 0,15 & 0,07 & 26,6 & 28,8 & 30,6 & 32,1 \\
\hline 1996 & 0,60 & 0,47 & 0,15 & 0,07 & 26,8 & 29,1 & 30,8 & 32,1 \\
\hline 1997 & 0,59 & 0,48 & 0,15 & 0,06 & 27,0 & 29,3 & 31,1 & 32,2 \\
\hline 1998 & 0,59 & 0,47 & 0,14 & 0,06 & 27,2 & 29,5 & 31,2 & 32,5 \\
\hline 1999 & 0,59 & 0,47 & 0,13 & 0,05 & 27,3 & 29,8 & 31,4 & 32,3 \\
\hline 2000 & 0,61 & 0,47 & 0,14 & 0,05 & 27,5 & 30,0 & 31,4 & 32,4 \\
\hline 2001 & 0,60 & 0,47 & 0,13 & 0,05 & 27,7 & 30,2 & 31,6 & 32,6 \\
\hline 2002 & 0,61 & 0,48 & 0,13 & 0,05 & 27,9 & 30,3 & 31,6 & 32,6 \\
\hline 2003 & 0,62 & 0,48 & 0,13 & 0,05 & 28,0 & 30,4 & 31,8 & 32,7 \\
\hline 2004 & 0,63 & 0,49 & 0,13 & 0,05 & 28,3 & 30,5 & 32,0 & 32,8 \\
\hline 2005 & 0,64 & 0,51 & 0,14 & 0,05 & 28,5 & 30,7 & 32,2 & 32,9 \\
\hline 2006 & 0,68 & 0,52 & 0,15 & 0,05 & 28,4 & 30,7 & 32,2 & 32,9 \\
\hline 2007 & 0,69 & 0,53 & 0,15 & 0,05 & 28,6 & 30,8 & 32,3 & 32,6 \\
\hline 2008 & 0,73 & 0,56 & 0,17 & 0,05 & 28,7 & 31,0 & 32,3 & 33,0 \\
\hline 2009 & 0,74 & 0,56 & 0,17 & 0,05 & 28,8 & 31,1 & 32,4 & 32,9 \\
\hline 2010 & 0,75 & 0,54 & 0,17 & 0,05 & 28,9 & 31,2 & 32,3 & 32,7 \\
\hline 2011 & 0,73 & 0,49 & 0,14 & 0,05 & 29,3 & 31,5 & 32,3 & 32,5 \\
\hline
\end{tabular}




\begin{tabular}{|l|l|l|l|l|l|l|l|l|}
2012 & 0,70 & 0,47 & 0,13 & 0,04 & 29,7 & 31,7 & 32,5 & 32,5 \\
\hline 2013 & 0,67 & 0,47 & 0,12 & 0,04 & 29,9 & 31,9 & 32,5 & 32,3 \\
\hline
\end{tabular}

\section{References}

[1] Adsera, A. 2004. "Changing fertility rates in developed countries. The impact of labour market institutions." Journal of Population Economics 17 (1): 1-27.

[2] Andorka, R. 1978. Determinants of fertility in advanced societies. London: Methuen \& Co.

[3] Becker, G. S. 1960. "An economic analysis of fertility. " In: Demographic and Economic Change in Developed Countries, Universities-National Bureau, UMI, pp. 225-256.

[4] Butz, W. P. and M. P. Ward. 1979a. "The emergence of countercyclical U. S. fertility." The American Economic Review 69 (3): 318-328.

[5] Butz, W. P. and M. P. Ward. 1979b. "Will US fertility remain low? A new economic interpretation. "Population and Development Review 5 (4): 663-688.

[6] Cutright, P. and Shorter, E. 1979. "The effects of health on the completed fertility of nonwhite and white U. S. women born from 1867 through 1935. " Journal of Social History 13 (2): 191-218.

[7] Easterlin, R. A. 1973. "Relative economic status and the American fertility swing. " In: Sheldon, E. B. (ed. ) Family economic behavior: problems and prospects. Philadelphia, Pennsylvania: J. B. Lippincott, pp. 170-227.

[8] Easterlin, R. A. 1976. "The conflict between aspirations and resources. " Population and Development Review $2(3-4): 417-425$.

[9] Fagnani, J. 2012. Work-family life balance: Future trends and challenges. In:OECD (ed. ). The Future of Families to 2030. OECD Publishing:119-187.

[10] Frejka, T. 2008. "Determinants of family formation and childbearing during the societal transition in Central and Eastern Europe. " Demographic Research, Special Collection 7, Vol. 19 (Article 7): 139-170.

[11] Goldstein, J. , Kreyenfeld, M. , Jasilioniene, A. , Karaman Örsal, D. 2013, "Fertility Reactions to the "Great Recession" in Europe: Recent Evidence from Order-Specific Data", Demographic Research,Vol. 29, Art. 4, pp 85-104.

[12] Hoem, B. 2000. "Entry into motherhood in Sweden: The influence of economic factors on the rise and fall in fertility, 1986-1997. " Demographic Research 2, Article 4.

[13] Hofmann, B. Hohmeyer, K. (2012). Perceived economic uncertainty and fertility. Journal of Marriage and Family 75: 503-521.

[14] Macunovich, D. J. 1996. "Relative income and the price of time: Exploring their effects on US fertility and female labor force participation. " In: J. B. Casterline, R. D. Lee, and K. A. Foote (eds. ) Fertility in the United States. New patterns, new theories. Supplement to Population and Development Review 22, New York, Population Council, pp. 223-257.

[15] Matysiak, A. and D. Vignoli. 2008. "Fertility and women's employment: A meta-analysis. " European Journal of Population 24: 363-384.

[16] Morgan, S. P. 1991. "Late Nineteenth and early Twentieth century childlessness." The American Journal of Sociology 97 (3): 779-807. 
[17] Morgan, S. P. 1996. "Characteristic features of modern American fertility". In. : J. B. Casterline, R. D. Lee, and K. A. Foote (eds. ) Fertility in the United States. New patterns, new theories. Supplement to Population and Development Review 22, New York, Population Council, pp. 19- 63.

[18] Philipov, D. and H. -P. Kohler. 2001. "Tempo effects in the fertility decline in Eastern Europe: Evidence from Bulgaria, the Czech Republic, Hungary, Poland and Russia. " European Journal of Population 17 (1): 37-60.

[19] Philipov, D. and J. Dorbritz. 2003. Demographic consequences of economic transition in countries of Central and Eastern Europe. Population Studies, No. 39, Council of Europe Publishing: Strasbourg.

[20] Rindfuss, R. R. , S. P. Morgan, and G. Swicegood. 1988. First births in America. Changes in the timing of parenthood. Berkeley: University of California Press.

[21] Schmitt, C. 2008. "Gender-specific effects of unemployment on family formation: A cross-national perspective. " DIW Berlin, Discussion Papers 841.

[22] Schmitt, C. 2012. A cross-national perspective on unemployment and first births. European Journal of Population 28 (3):303-335.

[23] Skirbekk, V. 2008. "Fertility Trends by Social Status. " Demographic Research 18 (5): 145-180.

[24] Sobotka, T. 2004. Postponement of childbearing and low fertility in Europe. PhD Thesis, University of Groningen. Amsterdam: Dutch University Press.

[25] Sobotka, T. 2008a. "Does persistent low fertility threaten the future of European populations?" In: J. Surkyn, P. Deboosere and J. van Bavel and (eds. ) Demographic challenges for the 21st Century. A state of art in demography. Brussels: VUBPRESS, pp. 27-89.

[26] Sobotka, T. 2008b. "The diverse faces of the second demographic transition in Europe. "Demographic Research, Special Collection 7, Vol. 19 (8): 171-224.

[27] Sobotka, T. , V. Skirbekk, and D. Philipov. 2011. "Economic recession and fertility in the developed world. A literature review. " Population and Development Review 37 (2): 267-306.

[28] Thévenon, O. 2011. Family policies in OECD countries: A comparative analysis. Population and Development Review 37 (1).

[29] UNECE. 2000. "Fertility decline in the transition economies, 1989-1998: Economic and social factors revisited". In. : Economic Survey of Europe 2000, No. 1. Economic Commission for Europe,

[30] Vikat, A. 2004. "Women's labor force attachment and childbearing in Finland. "Demographic Research, Special Collection 3 (Article 8): 177-212. 